\title{
Cuando la experiencia secuestrada se subleva: Sobrevivir la pandemial
}

Sección ESTUDIOS

RECIBIDO: 01/08/2021

APROBADO: 20/08/2021

PUBLICADO ONLINE: 30/12/2021

\author{
Elisabeth Acha Kutscher \\ Universidad Nacional Mayor de San Marcos \\ eachak@unmsm.edu.pe \\ https://orcid.org/0000-0001-6185-346x
}

\section{RESUMEN}

El artículo examina el impacto, a nivel académico y personal, de la pandemia Covid-19 en estudiantes de Ciencias Sociales de la Universidad Nacional Mayor de San Marcos (UNMSM) con el fin de establecer una agenda de investigación con perspectiva de género. Testimonios y conversaciones informales revelan, que el bienestar emocional y cognitivo se ha visto principalmente afectado a raíz de múltiples pérdidas, condición de encierro, contracción del presupuesto familiar lo que lleva al quiebre de la confianza básica. Adicionalmente, los resultados de una encuesta-diagnóstico aplicada en abril 2021 en conjunción con el Decanato de la misma Facultad permiten vislumbrar, dificultades en la gestión del tiempo y falta de condiciones adecuadas de estudio, a lo que se suma el incremento de las horas invertidas en tareas domésticas y labores de cuidado de familiares dependientes. Los hallazgos muestran igualmente la gran oportunidad que significa la pandemia para recrear una nueva normalidad. PALABRAS CLAVE: Pandemia Covid-19, estudiantes, salud mental, economía de cuidados, confianza básica

\section{When the sequestred experience rebels: Surviving the pandemic²}

\begin{abstract}
The impact of the pandemic Covid-19 on students of Social Sciences of the Universidad Nacional Mayor de San Marcos (UNMSM) will be examined in order to establish a research agenda from a gender perspective. Testimonies and informal conversations reveal that emotional and cognitive wellbeing had been fundamentally affected given multiple losses, conditions of confinement, contraction of family
\end{abstract}

1 Queremos brindar un profundo reconocimiento y agradecimiento a Luz Inés Parado Antonio, Aldana Yuselfi Ojeda Iliquín, María Angela Zelada Delgado, Thalia Candy Jara Mogollón y Romina Zanatti Olivares, estudiantes de la Facultad de Ciencias Sociales de la Universidad Nacional Mayor de San Marcos cuya participación en el taller de elaboración de diarios reflexivos fue indispensable.

2 En el inglés original (Giddens, 1990, p. 144), figura como the sequestration of experience.

(C) Los autores. Este artículo es publicado por la Revista de Sociología de la Facultad de Ciencias Sociales, Universidad Nacional Mayor de San Marcos. Este es un artículo de acceso abierto, distribuido bajo los términos de la licencia Creative Commons Atribución 4.0 Internacional (CC BY 4.0) [https://creativecommons.org/licenses/by/4.0/deed.es] que permite el uso, distribución y reproducción en cualquier medio, siempre que la obra original sea debidamente citada de su fuente original. 
budget that lead to the fracture of basic trust. In addition to this, the conduction of a questionnaire in April 2021 in conjunction with the Dean's Office discloses difficulties in the management of time and lack of adequate conditions to study in addition to the increment of time invested in domestic labor and care work of dependent family members. The findings also show how the pandemic offers a big opportunity to recreate a new normality.

KEYWORDS: Pandemic Covid-19, undergraduates, mental health, economy of care, basic trust.

\section{Introducción}

H an habido múltiples epidemias en la historia pero ninguna de la envergadura mundial como la actual. ${ }^{3}$ Para el PNUD (2020) el virus SARS-CoV-2, que causa la enfermedad respiratoria Covid-19, es síntoma del antropoceno, concepto sugerido por primera vez en el año 2000 por los científicos Crutzen y Stoermer, presentado luego en la revista Nature en 2002. La humanidad se ha convertido en una poderosa fuerza geológica comparable con la voluptuosidad de los ríos caudalosos y la intempestiva erupción de los volcanes (Latour, 2017, p. 137; Tieschler, 2017). Latour (2017), siguiendo a Lovelock y Margulis, toma la figura mítica de Gaia, criatura de la necesidad y del azar, sin centro ni operador externo, que surge del caos en los albores de la creación, como hipótesis del antropoceno. Bajo esta perspectiva, SARScoV-2 podría ser identificado como un cuasi-sujeto con agencia y gran potención de actuación, capaz de postrar al mundo entero bajo su amenaza, que manipula bajo interés propio que los demás se adapten a su propio ambiente (Latour, 2017, p. 164). Atrás quedó la imagen de una naturaleza benévola que está allá afuera como un todo unificado, ordenado, estable y equilibrado con capacidad de homeostasis para dar pie a la confusa, desordenada y problemática Gaia, un “lindo revoltijo", resultado de "todas las consecuencias entremezcladas e imprevisibles de las posibilidades de actuar" del cual formamos parte (Latour, 2017, pp. 119, 164).

3 Epidemias que trajeron desolación hubo en el Perú al llegar los conquistadores, 1718-1723 (no existe claridad qué lo causó), paludismo, dengue y escarlatina entre 1818 y 1821, fiebre amarilla en 1868, diseminación de peste bubónica entre 1903 y 1930, fiebre amarilla entre 1919 y 1922, malaria en la década de 1920, cólera en 1991. Uno de los ataques epidémicos más pavorosos se produjo durante la conquista a raíz de la propagación de la viruela en la década de 1520, seguido del sarampión a comienzos de 1530 y tifus o influenza neumónica entre 1545 y 1547 lo que ocasionó una verdadera catástrofe demográfica (Cook, 2010, pp. 22-23). La peste negra cobró aproximadamente cien millones de vidas en Asia, África y Europa en el siglo XIV. El antecedente más parecido a la situación que estamos viviendo actualmente fue la embestida de la influenza española entre 1918 y 1920 que resultó en 70 millones de víctimas en un proceso de tres arremetidas, cifra mayor que el número de personas caídas durante la Primera Guerra Mundial y Segunda Guerra Mundial en cada caso. Los medios de comunicación españoles fueron los primeros en difundir la noticia, de allí el nombre equivoco a una pandemia que se originó en un campamento militar en Kansas del país del norte. De manera similar a la actualidad, la manera de combatirla fue a través de cuarentenas, aislamiento de los enfermos, uso de mascarillas, prohibición de todo evento que significara la reunión de multitudes (Lossio, 2021). 
Luego de presentar el procedimiento metodológico seguido, se muestra el panorama de las víctimas de la pandemia Covid-19 a nivel mundial en cifras para pasar seguidamente a examinar el impacto de la crisis desatada en las distintas dimensiones y "nudos estructurales" de la desigualdad de género (CEPAL, 2021). Finalmente, se da paso a un ordenamiento de temas para la agenda de investigaciones sobre el impacto de la pandemia Covid-19 en estudiantes universitarios.

\section{Examinando el impacto del Covid-19 en estudiantes universitarios}

\subsection{Procedimiento metodológico empleado}

El primer semestre (2020-1) en pandemia Covid-19 develó una compleja situación que quizá no hubiera sido mostrada en otras circunstancias. Hubo largos silencios incomprensibles, comunicación cruzada y repentino abandono de cursos de parte de varios estudiantes. Urgía conocer más de cerca las condiciones en las que los estudiantes estaban llevando a cabo esta virtualidad y el tipo de impactos que la crisis de la pandemia Covid-19 había desatado.

Durante el semestre 2020-2 convocamos a los estudiantes del Taller de Investigación Sociológica Il en modalidad virtual de la Escuela de Sociología de Facultad de Ciencias Sociales la UNMSM para trabajar - a partir del registro de un diario reflexivo - el impacto y vivencia personal de la pandemia. De por medio habían múltiples propósitos. Principalmente la meta era empezar a documentar la crisis externa e interna y con eso poder comprender el impacto de la situación en los estudiantes, además de agudizar la capacidad de observación y descripción de los acontecimientos en sus diversas dimensiones y al mismo tiempo, profundizar el auto-entendimiento de una misma. De un total de 24 estudiantes (18 de sexo femenino y 6 masculino), se interesaron seis de manera voluntaria, quedando finalmente en octubre del 2020 un grupo conformado por cinco alumnas mujeres de 20, 22 (dos casos), 24 y 28 años de los distritos del Cercado de Lima (y que cada tres meses se traslada a Chachapoyas en Amazonas), San Miguel, San Martín de Porres, San Borja y Santiago de Surco respectivamente. El consentimiento informado fue realizado oralmente, las entregas fueron recibidas vía correo electrónico y los textos sujetos a mutuas reflexiones y retroalimentación con el propósito de lograr mayor claridad en la descripción en encuentros grupales a través del google-meet. Para comunicarnos también recurrimos a mensajes vía WhatsApp. Todo este proceso, que fue conducido con mucho cuidado, se llevó a cabo entre octubre 2020 y marzo del 
2021. Hablar de una misma sobre temas sensibles nunca es fácil. Hubo momentos de silencio donde dejamos de comunicarnos. Los extractos de testimonios que citamos a lo largo del artículo provienen de esta experiencia de taller.

Adicionalmente, en acuerdo con el Decanato de la Facultad de Ciencias Sociales de UNMSM, surge también la idea de realizar un diagnóstico integral de los estudiantes de la Facultad en pandemia, para lo cual elaboramos y aplicamos una encuesta (de ahora en adelante Diagnóstico 2021) vía el Sistema Único de Matrícula (SUM) de UNMSM entre el 22 y 30 de abril 2021. Dicha encuesta, cuyos participantes voluntariamente accedieron a participar en este estudio, fue respondida por 581 de 1475 estudiantes de las seis escuelas de la Facultad ${ }^{4}$ que se matricularon en el 2021-1, de las distintas bases 2014 a 2018, siendo las bases que aglutinaron el mayor número de respuestas fueron 2018 (140) y 2016 (123) (307 de sexo femenino, 269 de sexo masculino). La encuesta ayudó a precisar mejor el perfil de los estudiantes de la Facultad de Ciencias Sociales de la UNMSM ${ }^{5}$ y ampliar el panorama de temáticas complementarias que habría que seguir desarrollando. ${ }^{6}$

Ambos momentos de generación de información no corresponden a un mismo proyecto, además de tener objetivos distintos, sin embargo, ayudaron a identificar distintas dimensiones de la problemática en mención.

\subsection{Diario personal y reflexividad en la investigación}

Los testimonios derivados de los diarios escritos por cinco alumnas de la Escuela Profesional de Sociología realzan cómo la crisis desatada por la pandemia Covid-19 ha quebrado drásticamente las rutinas establecidas y exacerbado el sufrimiento derivado de tener que enfrentar casos de familiares con Covid-19, las muertes inesperadas y el encierro. De manera paralela, aparecen las dificultades entre gestionar tiempo para estudiar, cuidar de los enfermos y personas dependientes y cumplir con las labores domésticas del hogar junto con tener que vivir con la incertidumbre económica.

4 La Facultad de Ciencias Sociales de la UNMSM está compuesta por las escuelas de sociología (321), trabajo social (352), historia (185), geografía (226), arqueología (163) y antropología (228). Entre paréntesis citamos el número de estudiantes por escuela.

5 La mayoría de estudiantes de la muestra han nacido en Lima (77\%) seguido de la Provincia Constitucional del Callao. Igualmente existen estudiantes nacidos en Ancash (19 casos), Junín (13), Ayacucho (9), Amazonas (6), Apurímac (5), Piura (5), Puno (4) principalmente.

6 Contamos en todo momento con el magnífico apoyo de Erik Chachuricra, Jefe de Informática de la Facultad de Ciencias Sociales para su difusión y colocación de avisos que aparecieron en la página Facebook de la Facultad. Carla Toche realizo el análisis de frecuencias) y Junior Pérez el de las preguntas abiertas. En todo momento Dr. Cristóbal Aljovín, Decano de la Facultad, y la Dra. Carlota Casalino, Vicedecana Académica, cumplieron un rol fundamental en llevar adelante este cometido. 
Reflexionar es un ejercicio que se asemeja a un "doblarse para atrás" imaginariamente sobre el cuerpo mismo (Castro y Uribe, 1998, p. 37). ${ }^{7}$ La reflexividad y toma de consciencia de lo que somos, el estar más presente y en conexión con el mundo de la vida ${ }^{8}$, es algo característico de la acción humana. Los agentes están preparados para proveer razones acerca de qué hacen y por qué lo hacen. Reflexividad implica descentramiento de la propia posición, efectuar la "ruptura epistemológica" para poder diferenciar "la interpretación científica del funcionamiento social" (Bourdieu, Chamboredon, Passeron, 1979, p. 41). La triangulación de las perspectivas teóricas y métodos es una manera de instituir la reflexión en el proceso de investigación.

Investigar implica reflexividad y estar obligados a una"polémica ininterrumpida con las enceguecedoras evidencias que se presentan, a bajo precio, las ilusiones del saber inmediato", la familiaridad con el mundo social (Bourdieu, Chamboredon y Passeron, 1979, p. 27). La reflexividad que incorpora el bagaje teórico y el de sentido común, nos invita a realizar un diálogo activo entre las diversas dimensiones del acto de investigar que no se limita "aplicar unidireccionalmente los modelos teóricos al referente" (Guber, 2005, pp. 48-49). 'La sociología no puede quedarse en transmitir lo que los propios actores dicen (Dubet, 2012, p. 29).

La conducción de un diario personal nos permite reconstruir los acontecimientos y analizar lo ocurrido en forma retrospectiva y sosegada, además de darnos cuenta del contexto en el que ha ocurrido y las dimensiones que han intervenido (Bardají, 2008). Escribir un diario es siempre dar cuenta de algo que ya sucedió. Desde una perspectiva fenomenológica, "sólo vivencias pasadas pueden ser significativas a partir de un acto reflexivo de atención" y no tanto mientras estamos realizando actividades. Solamente tiene sentido una experiencia propiamente dicha cuando ha sido consumada, cuando es posible identificar un comienzo y fin

7 Ganar consciencia somática o corporización implica estar alerta de lo que sucede al interior del cuerpo lo que conduce a una mayor sarcalidad, es decir, sentimientos de abundancia, placidez y esperanza (Castro y Uribe, 1998, pp. 35 y 37). En otras palabras, para la disciplina de educación somática, la reflexividad y exploración del soma (experiencia fenomenológica del cuerpo) y de las emociones conduciría a incrementar al bienestar de las personas con la posibilidad de aliviar dolencias físicas e internas como duelos inconclusos generando mayor consciencia somática.

8 Mundo de la vida (Lebenswelt) es un concepto creado por Edmund Husserl como parte de su fenomenología que integra diversas realidades y modos de experiencia. El nivel primordial del mundo de la vida es la vida cotidiana a la que le corresponde un saber específico que es el sentido común. La idea es que todo conocimiento surge desde el mundo de la vida, lugar que el sujeto participa y no solamente observa (Nugent, 1991).

9 De otro lado, Giddens añade el concepto de "reflexividad instituida de la modernidad" (intitutional reflexivity of modernity) distinta al monitoreo reflexivo de la acción como actitud intrínseca del ser humano, se refiere al escrutinio y revisión constante de los diversos aspectos de la vida a la luz de la generación de nuevos conocimientos e información difundidas a todo nivel, incluso más allá de la ciencia misma (Giddens, 1992: 20). La sociología y ciencias sociales también contribuyen a esta reflexividad institucional. 
definidos (Krause, 2013, p. 19). En la interpretación de los hechos también influye nuestra historia personal, la familia de donde provenimos y el sistema cultural que internalizamos.

Un rubro a ser investigado y que excede los propósitos de este artículo, es examinar si existe una diferencia en cuanto la expresión de sentimientos en varones y mujeres. La cultura masculina imperante enseña a los hombres a mostrarse competitivos, agresivos e insensibles (Fuller, 2001, p. 172) ¿En qué medida eso significaría tener mayores dificultades para hablar y escribir sobre sus propias emociones?

\section{Contexto de la pandemia Covid-19}

A través del Plan Nacional de preparación y respuesta frente al riesgo de introducción del Coronavirus 2019-ncov del primero de febrero 2020 (Resolución Ministerial 039-2020/MINSA), el Estado peruano quiso evitar que el virus llegue al Perú. La situación, sin embargo, se precipitó rápidamente. El sistema de salud colapsó irremediablemente en los meses que siguieron.

La Organización Mundial de la Salud (OMS) declaró el 11 de marzo del 2020 SARS-CoV-2- como pandemia. El gobierno peruano decretó mediante DS №442020-PCM, cinco días después, Estado de Emergencia, restringiendo los derechos constitucionales, siendo el primer país en América Latina que tomó este tipo de medidas para enfrentar este mortal virus.

De acuerdo al registro de la Universidad Johns Hopkins ${ }^{10}$, a nivel global, el Covid-19 ha cobrado 5.193.296 decesos al 27 de noviembre de 2021, siendo los Estados Unidos (776.385) y Brasil (613.957) los dos países que han sufrido el mayor número de pérdidas en términos absolutos, seguidos de India (467.933) y México (293.614). Las grandes ciudades de Brasil están contabilizando más muertes que nacimientos. ${ }^{11}$ En medio de esta pavorosa catástrofe, la crisis de oxígeno y falta de vacunas, la situación sanitaria en la India se ha desbordado. Las noticias encontradas en mayo 2021 reportan que en calles y plazas se observan piras funerarias. Una verdadera hecatombe para la humanidad.

Hacia junio del 2021, el Perú se ubicó, muy a nuestro pesar, como uno de los países con el número mayor de fallecimientos por Covid-19 en el mundo por cada

10 Seguir el siguiente enlace de la Johns Hopkins University https://coronavirus.jhu.edu/map.html

11 Jucá, B., Gil Alessi, Felipe Betim y Naira Hofmeister (14 de abril 2021). Las grandes ciudades de Brasil empiezan a registrar por la pandemia más muertes que nacimientos. El País. https://elpais.com/sociedad/2021-04-15/ brasil-registra-mas-muertes-que-nacimientos-por-el-descontrol-de-la-pandemia.html 
millón de personas, situándose en el quinto lugar con más muertes en términos absolutos. ${ }^{12}$

La pandemia Covid-19 ha puesto en evidencia de manera descarnada los devastadores abismos sociales y económicos del país: el hecho de ser un país fracturado, escindido. Al 22 de mayo 2021, el Ministerio de Salud reportó 67,807 fallecidos a nivel nacional debido al Covid-19. Seis meses más tarde, el Ministerio de Salud registró 200,961 decesos al 24 de noviembre 2021 sin contar los casos que no han podido ser notificados, mientras que la Johns Hopkins Coronavirus Resourse Centener reportó para el Perú al 27 de noviembre 201.026 víctimas. En año y ocho meses de pandemia el número de decesos está superando el número de víctimas habidas durante el conflicto armado interno (1980-2000) que, de acuerdo a la Comisión de la Verdad y Reconciliación, la cifra más probable fue de 69,280 (CVR, 2003. Tomo VIII, p. 253). En este lapso de tiempo, se han producido casi tantos fallecimientos por Covid-19 como víctimas habidas en veinte años de pugna sangrienta por la conquista y defensa del Estado cuyo principal responsable fue el PCP-SL. ${ }^{13}$

Indudablemente ha habido grandes dificultades de parte del Estado para informar acerca de la envergadura del problema y la seriedad de las medidas de prevención sobre las formas de contagio del SARS-CoV-2. No sabemos qué porcentaje de contagiados se debe a la desconexión y desconfianza de la población hacia el Estado que aparece como una entidad poco confiable y creíble como la señala Lossio (2021).

\section{Cuando la experiencia secuestrada se subleva}

Irrumpen situaciones inesperadas como da cuenta el siguiente testimonio de una de las estudiantes que participó en el taller mencionado más arriba, donde en medio de una situación de horror surgen muestras de solidaridad.

En estas dos últimas semanas han muerto tres vecinos de mi barrio. La última fue el miércoles, mi vecina Cristina. Desde ese día hasta el viernes estuve cuidando a los cuatro nietos de mi vecina que falleció de COVID, fue una situación excepcional ya

12 Médicos sin fronteras (04.06.2021). Perú es oficialmente el país del mundo más afectado por la Covid-19.

13 "La CVR considera que la causa inmediata y fundamental del desencadenamiento del conflicto armado interno fue la decisión del PCP-SL de iniciar la "lucha armada" contra el Estado peruano, a contracorriente de la abrumadora mayoría de peruanos y peruanas, y en momentos en que se restauraba la democracia a través de elecciones libres" (CVR, 2003. Tomo XVIII, p. 355) 
que no conocemos a su familia cercana. Felizmente nosotros tenemos un departamento en el primer piso, los tuvimos aislados. Bueno, ahora están con su mamá.

La humanidad siempre ha sentido la necesidad de ritualizar y domesticar, a través de diversas ceremonias, el hecho de no ser eternos. En Occidente, la muerte habría estado asociada a la adversidad, al mal en sus variadas versiones, al sufrimiento, castigo, pecado, a lo demoniaco (Aries, 2008, p. 605). En la era de la primera modernidad, la muerte dejó de ser un suceso inmediato y familiar para convertirse en algo remoto.

Secuestro de la experiencia alude al encubrimiento de una serie de situaciones que si se mostrarían de manera descarnada, perturbarían el trascurrir de la vida cotidiana como una de las tareas centrales de las instituciones del Estado moderno (Giddens, 1995, p. 199). Los sistemas expertos y el Estado se encargaron de secuestrar la enfermedad, la locura y la muerte lejos de la vista pública. Esta retención, sin embargo, no es total. A partir de la catástrofe de Chernóbil del 26 de abril 1986, entró a tallar, la sociedad del riesgo mundial (Beck, 2017), entendiendo el riesgo como adelanto a la posibilidad de una catástrofe perentoria. Vivimos épocas inciertas y paradójicas si pensamos en las consecuencias y costos de las medidas de seguridad que intensifican el miedo y la incertidumbre. ${ }^{14}$

El secuestro de la experiencia se subleva, se desata un torbellino de emociones y preguntas existenciales que habían quedado en suspenso. La muerte pareciera estar acorralando a la vida progresivamente.

La cercanía de la muerte es inminente y no podemos hacer nada para evitarla. ¿Cómo se supone que deberíamos sentirnos al perder de pronto a varios de nuestros seres queridos? Nunca antes había experimentado todas esas emociones juntas, mucho menos en esa magnitud. Era realmente desesperante vivir aquello, pero más desesperante era recibir noticias de familiares y amigos cercanos que fallecían a diario.

Llevar a cabo una rutina requiere una inyección de seguridad ontológica y consciencia práctica que coloca entre paréntesis la posibilidad repentina de sucesos que

14 La semántica del riesgo (Beck, 2017, p. 20) en épocas actuales difiere de la Edad Media, donde la enfermedad, la muerte prematura, hambrunas y epidemias era lo común. Hoy en día se vincula con "riesgos futuros que se tematizan en el presente y resultan a menudo de los éxitos de la civilización" (Beck, 2017, p. 20). Un riesgo entraña la posibilidad cercana de una catástrofe, de una amenaza expresada en ideas y sentimientos que impactan en las decisiones de la vida cotidiana, dimensión que supone la suspensión de preocupaciones existenciales, evitando el resquebrajamiento de la confianza y fe interna sobre la cual se anclan las tareas más simples del diario convivir. 
amenacen nuestra integridad física y emocional (Giddens, 1995). La confianza básica de la cual se deriva la seguridad ontológica y consciencia práctica, proviene de las primeras experiencias emocionales. La confianza generalizada como dispositivo, coraza protectora, núcleo de esperanza más importante que permite actuar como si nada fuera a pasar, es lo que permite deslizarnos por la vida. Algunas personas estarían mejor equipadas que otras para enfrentar contratiempos, ser más resilientes ante las fatalidades y eso dependería mucho de factores personales (y añadimos sociales) que se han conjugado en la vida: calidad de redes sociales y familiares, acceso a servicios sociales y de protección, todo esto dentro de un marco cultural (Naciones Unidad de Colombia et al, 2020). ${ }^{15}$

\section{Las múltiples crisis derivadas de la pandemia Covid-19}

\subsection{Exacerbación de las brechas socio-económicas}

¿Cómo fue vivida la crisis económica por los estudiantes?

Llegó el mes de junio y los gastos de servicios como agua, luz y gas se habían elevado totalmente, sobre todo, de luz y gas, pues estos se habían triplicado. Pero esto era descabellado; ya que, los tres meses de cuarentena habíamos cancelado y con montos bien altos. A simple vista era un abuso; dado que, es imposible consumir tres veces de lo normal en un solo mes más aún cuando habíamos utilizado los servicios de manera ahorrativa. Tuvimos que reclamar, pero esto fue toda una odisea; ya que, había colas enormes todos los días, pues había mucha gente reclamando por la misma situación. Cuando finalmente nos atendieron y pedí la explicación del caso, descubrimos que realmente era un robo descarado a tal punto que el personal atinó a decir que ellos solo cumplían órdenes. ¿Por qué el Estado no hace nada ante los abusos de estas empresas?

Cerca del 50\% de la muestra de estudiantes del Diagnóstico 2021, declara un deterioro en la propia situación económica. De otro lado, se trataría de una poblacion donde un poco más de un tercio de los estudiantes (34\%, es decir 198 casos de la muestra) realizan trabajos remunerados de los cuales, salvo en 58 casos, la mayoría (140) se desempeña en labores relacionadas con la formación profesional.

15 Surge la pregunta de cuán cimentada se encuentra la confianza básica en los y las estudiantes y de cómo su calidad afecta su desempeño académico. Esta sería una tarea pendiente de ser absuelta a nivel de la UNMSM, conjuntamente con el Centro de Salud Mental Comunitario con el fin de brindar una mejor atención a los estudiantes. 
Trabajar en pandemia conlleva riesgos. Más de la mitad de los que trabajan se han visto obligados a salir de sus hogares a cumplir jornadas presenciales durante la pandemia (61\% que corresponde a 122 casos). De otro lado, $48 \%$ ( 280 casos) señala haber estado buscando activamente trabajo en el momento de la encuesta (fines de abril 2021).

El gran malestar que ocasiona esta crisis a nivel académico se expresa claramente a través de estas líneas:

Sin recursos económicos y con una salud resquebrajada mis metas trazadas se alejan cada vez más. Egresar, obtener el grado de bachiller, hacer la tesis y conseguir empleo de acuerdo a mi formación suenan a un sueño lejano imposible de alcanzar en la situación en la que me encuentro, ya que, aún ni siquiera estoy segura de continuar con el ciclo regular de este año.

De acuerdo a la CEPAL (2021), la pandemia Covid-19 repercutió con dureza en América Latina y el Caribe "en un contexto de bajo crecimiento económico y aumento de la pobreza y las desigualdades".

En términos comparativos (trimeste noviembre-enero) entre 2020 y 2021, los porcentajes de población ocupada cayeron en $11.9 \%$ en Lima Metropolitana. Las mujeres fueron las más afectadas con un 15.3\%, en comparación con el $9 \%$ de disminución en el caso de los varones. ${ }^{16}$ En cierto sentido, la crisis sanitaria estaría afectando más a las mujeres que a los varones, tomando en cuenta que es sobre ellas donde recae generalmente la responsabilidad de las labores domésticas y la crianza de los hijos e hijas (Mannarelli et al 2020). La capacidad adquisitiva de los hogares ha sido tremendamente afectada y se ha reducido en casi un $25 \%$ en el último año afirma Farid Matuk. ${ }^{17}$

Comercio y servicios son dos de los sectores en el Perú que están siendo más golpeados por la crisis desatada por el encierro por la pandemia Covid-19. El 44\% de la PEA femenina se dedica a los servicios en contraste con el $37 \%$ de la PEA masculina de acuerdo a datos trabajados del INEI-Enaho del 2018 y 2019 por Jaramillo y Ñopo (2020). Como constatamos, ambos rubros emplean en su mayoría mujeres a diferencia de las industrias extractivas y de construcción (Jaramillo y Ñopo, 2020). El trabajo femenino, a diferencia del masculino se compone de trabajos a tiempo

16 INEI. Situación del mercado laboral en Lima Metropolitana. Trimestre móvil: Noviembre-diciembre 2020-enero 2021. №2. Febrero 2021. Cuadro 3, p. 4. https://www.inei.gob.pe/media/MenuRecursivo/boletines/02informe-tecnico-mercado-laboral-nov-dic2020-ene2021.pdf

17 Bessombes, Ca. (16 de abril 2021). Recesión afecta más a hogares que a empresas. País. Economía. La República, p. 14. 
parcial, autoempleo, informalidad y empleo en establecimientos de menos de cinco trabajadores. Esta información levanta un tema importante que nos llevaría en un futuro analizar la ocupación de los padres y madres.

\subsection{Enfrentando la virtualidad de los cursos}

¿Cuáles son las condiciones en las que se desenvuelve la virtualidad en los y las estudiantes?

$16 \%$ (91) de estudiantes de la muestra han abandonado algún curso durante 2020-II debido a problemas tanto de salud mental y física, carga laboral y dificultades de tiempo en general.

$43 \%$ (251) declara no contar con una mesa de trabajo. 41\% (238) afirman que el principal dispositivo para conectarse a los cursos en la modalidad virtual ha sido una lap top, mientras que un 32\% (185) afirma ha sido a través de un teléfono celular. 19\% (108) dispone de una PC. Los demás se conectan a través de una tablet.

A la pregunta de: “En promedio ¿cuántas horas al día has utilizado algún dispositivo para poder estudiar y hacer tus tareas durante 2020 ?" $15 \%$ (86) de la muestra responde haber invertido cinco horas, mientras un 16\% (95) seis horas y $42 \%$ (245) ocho horas al día en promedio. En suma, la gran mayoría invierte entre 5 y 8 horas al día de trabajo en pantalla, sin embargo, al mismo tiempo habría que examinar la diversidad de estrategias utilizadas para poder sobrevivir tal carga de trabajo.

Virtualidad significa agotamiento y habría que seguir examinando la envergadura de esta realidad.

Las clases virtuales han sido muy agotadoras en todos los sentidos, hasta los problemas de miopía en la vista se me han agravado. Este año es muy incierto para mí y no sé cuánto más seguiré así, solo sé que mientras dure la pandemia mi situación, la de mi familia y muchos peruanos más se irá agravando si no se logra contrarrestar la crisis general.

¿Cuáles son las ventajas y desventajas a nivel académico de la virtualidad? De un lado, coinciden los estudiantes, en conversaciones informales sostenidas, que una gran ventaja es no verse obligados a trasladarse hasta la UNSMS, sobre todo cuando eso implica emplear dos a cuatro horas diarios de permanecer dentro de un transporte público. La virtualidad permite viajar, comunicarse desde sus trabajos y realizar varias actividades al mismo tiempo (que es la parte no dicha o confesada), chatear, estar al cuidado de otros, atender dos cursos paralelos a la vez o estar realizando alguna labor doméstica. 


\subsection{Trastocamiento de los tiempos en la vida cotidiana}

Hemos señalado que un 16\% (91) de la muestra responde haber abandonado algún curso durante 2020. Entre las respuestas que se esgrimen a partir de la pregunta abierta de ¿por qué razón abandonaste algún curso en 2020? Está el agotamiento y la falta de dispositivo electrónico adecuado para la recepción de las clases virtuales. También está el la falta de tiempo, "me resultó difícil la interacción virtual en clase", problemas de salud mental (depresión, estrés, ansiedad, inestabilidad emocional y/o desmotivación), familiares que han contraido Covid-19. La rutina se quiebra y los estudiantes enfrentan un vendaval de emociones encontradas y un trastocamiento de los tiempos.

Surge un embrollo de tiempos destinados para cuidar, trabajar y estudiar lo que obliga a tomar decisiones de distinta índole, expresado en la siguiente cita.

Los desacuerdos se dan cuando, al mismo tiempo, mi hermana y yo requerimos de tiempo para realizar nuestras propias actividades. A veces eso también sucede con mi mamá. Cuando quiero tiempo para mí y mi hermana no puede quedarse a cargo de nuestros hermanos menores, las dos terminamos molestas. Así que generalmente dejo mi puerta abierta (para vigilar a mis hermanos) o les pongo un video en el celular y hago lo que tengo pendiente en la laptop. Me demora más y me desconcentra, pero funciona.

Cuando mis hermanos se hospitalizaron (fue en diferentes momentos) mi mamá fue quien más tiempo estuvo en el hospital cuidándolos, pero por el trabajo y el agotamiento necesitaba relevos. Felizmente la hospitalización, en ninguno de los dos casos, duró más de quince días. Y en ningún caso fue por Covid-19.

¿Quién cuida de los hermanos menores?

Mi hermano menor había contraído el virus del Covid-19. En todo ese tiempo tuve que hacerme cargo de su cuidado lo que, sin duda, no fue nada fácil. Una semana de desconcierto, tristeza, desesperación, amargura, impotencia y somnolencia.

El Diagnóstico 2021 señala que la gran mayoría de estudiantes (88\%, 511 casos) apoya en las labores domésticas. Habría que seguir indagando si nos hallamos frente a una generación de jóvenes que rompen con el estereotipo de pensar que son básicamente las mujeres las que se dedican a las labores del hogar.

La pandemia no necesariamente ha traído una situación nueva de falta de tiempo debido al torbellino de actividades que antes de la pandemia conducía en estudianes, al mal hábito de comer cualquier cosa de manera ansiosa sin detenerse a 
tomar asiento, a comer parada mientras se camina al entrar a salir de la universidad o al interior del transporte público. La situación de pandemia crea la oportunidad de reflexionar y analizar los hábitos alimenticios, incorporar mayor cantidad de frutas y verduras en la dieta cotidiana, "dejar de comer comida chatarra" y "dejar los antojitos de lado".

Resulta crucial recuperar la variable perdida del análisis económico tal como lo menciona Lavado (2017) que es el recurso tiempo y volver aplicar la Encuesta Nacional del Uso del Tiempo (ENUT) del 2010 del Instituto Nacional de Estadística e Informática (INEI) con el fin de conocer a nivel nacional cómo se ha ido modificando la carga y distribución, por ejemplo, del trabajo doméstico no remunerado al interior de las familias y cuál ha sido la repercusión en la calidad de vida ahora en pandemia. El tiempo es un recurso valioso de ser tomado en cuenta en los análisis del tiempo global de las personas en general. Usualmente la pobreza material se asocia a la pobreza de tiempo.

Lavado (2017) encontró a partir de los datos proporcionados por el ENUT 2010 del INEl, que el número de horas invertidas en las labores domésticas y el cuidado de personas dependientes aumenta significativamente a 53 horas semanales en los casos de mujeres con hijos dentro del quintil de ingresos más bajos en comparación con mujeres sin hijos que destinan a partir de 33 horas semanales. En el caso del quintil más alto de ingresos, el tiempo invertido en el mismo rubro es de 34 horas semanales para mujeres con hijos y 18 para mujeres sin hijos.

En términos generales, aspectos como acceso al agua, combustible para cocinar, contar con artefactos eléctricos que alivien el trabajo doméstico también son aspectos a tener en cuenta en cuanto inversión de tiempo destinado a diversas actividades. No es lo mismo que acarrear baldes de agua a través de laderas que abrir el caño para contar con agua para cocinar. Igualmente lavar a mano que hacerlo con la ayuda de una máquina de lavar.

¿Quién cuida a quién, dónde, en qué tipo de circunstancias y quién asume los costos del cuidado? ¿Cómo se distribuyen las labores domésticas al interior de los hogares? ¿Cuánto tiempo libre me queda para estudiar? ¿Cuánto es el tiempo disponible para realizar trabajos remunerados? ¿Quién es la autoridad qué decide la dinámica familiar al interior de los hogares? Son temas importantes a ser aclarados, ahora que el confinamiento ha puesto en evidencia la importancia del cuidado al interior de las familias. Cuidar implica esfuerzo, recursos y una inversión importante de tiempo. Se trata de una labor diaria que tendría que asegurar una alimentación balanceada, velar por un sueño tranquilo y profundo, garantizar la higiene adecuada para evitar la proliferación de enfermedades, así como promover 
el bienestar tanto físico como emocional de las personas. Vivimos una época de crisis de la economía del cuidado (Fraser, 2019). El tiempo destinado al cuidado y atención de las personas resulta escaso. Los cuidados son indispensables para la reproducción de la vida (Battyány, 2019; Federici, 2019; Fraser, 2019; Pérez, 2019). Las labores de cuidado Ilevadas a cabo en el ámbito privado, permite reponer la fuerza de trabajo de tal manera que pueda reproducirse de manera sostenida (Lavado, 2017) Paradójicamente, a pesar de su importancia y contribución a la economía, el trabajo doméstico no remunerado junto con las labores de cuidado, no cuentan con el debido reconocimiento, prestándose incluso a estigmas sociales frente al trabajo remunerado que goza de mayor prestigio y atención (Lavado, 2017).

Más que nunca, la sociología tendría que interactuar con las ciencias y disciplinas encargadas de la salud mental para comprender la envergadura de las secuelas de la pandemia a este nivel, más aún en personas que arrastran consigo situaciones previas que desbordan la capacidad para procesarlas. El trauma se reedita en sensaciones viscerales, corporales de ansiedad y pánico sin saber de dónde proceden esas sensaciones instaladas en el cuerpo (Levine, 2015). Cuando esta situación se da, existe la imperiosa necesidad de no seguir drenando energías en especulaciones negativas que añaden cuotas de sufrimiento que podrían ser revertidas como energía a nuestro favor, mejor aún si lo hacemos en equipo, acompañados de demostraciones de solidaridad mutua lo que nos lleva al tema de la economía de cuidados que lejos de ser una temática meramente personal atañe al Estado (Battyány, 2019, p. 156).

Lavado (2017) examina la feminización del trabajo doméstico a partir de la división sexual del trabajo, conceptualizada por Durkheim en 1893 que refuerza la idea de atribuir la responsabilidad como proveedor exclusivo a los varones, quedando la mujer confinada a los cuidados del hogar desde una perspectiva de familia nuclear biparental. Esta situación se ha modificado. Las mujeres salen a trabajar y los hogares monoparentales se han incrementado. Sin embargo, al mismo tiempo, no existen signos de "rapidez de inserción de los hombres en los trabajos domésticos" (Lavado, 2017).

\subsection{Estructura familiar y soporte moral}

La estructura familiar varía en el caso de los estudiantes de la Facultad de Ciencias Sociales de la UNMSM. Un 38\% (222) de la muestra del Diagnóstico 2021 señala vivir en familias biparentales con hermanos y hermanas. 23\% (134) declara vivir solamente con la madre. Luego existen circunstancias de lo más variadas desde vivir solo, con el padre, con otros hermanos o parientes. La cuarta parte de hogares 
se compone de cuatro miembros y luego existen diferentes situaciones entre dos extremos donde 52 estudiantes mencionan vivir solamente con una persona adicional y 31 que señalan vivir en espacios de más de diez personas. Aparentemente entonces, el hacinamiento no es la norma en los estudiantes.

A la crisis económica y pérdidas de vidas humanas se suma el confinamiento que agudiza tensiones y hostilidades previamente existentes en el hogar.

Lo más difícil que me tocó vivir durante la pandemia fue tener que convivir con mis padres y escucharlos pelear a diario. Con la pandemia la relación entre mi madre y mi padre empeoró aún más. No sabía ni cómo intervenir frente a las constantes agresiones entre ambos. Soy consciente que mi familia es disfuncional, creo que por eso desde chica trate de meterme en actividades como para evadir esa convivencia (primero con libros, la iglesia, saliendo con amigxs, luego la universidad, voluntariados, etc.) Encontré en la pintura un espacio para poder relajarme y expresarme, olvidar por un momento todo.

En el Perú ha habido cambios significativos en cuanto a la estructura familiar y jefatura femenina de los hogares que creció 127\%, entre 2001 y 2018, en contraste con los de jefatura masculina que lo hizo en un 35\%. Un 38\% de los hogares son monoparentales (Jaramillo y Ñopo, 2020, p. 8). De acuerdo al Censo del 2017, $34,7 \%$ de hogares estarían encabezados por mujeres junto con la tendencia en el comportamiento de varones que haber desertado en asumir su responsabilidad como padres. Los hogares encabezados por mujeres tienden a vivir más en espacios alquilados y no en casa propia que aquellos de jefatura masculina, poseen menos activos (artefactos electricos, dispositivos, vehiculos de algún tipo, etc) (Jaramillo y Ñopo, 2020, p. 10).

Cerca del $84 \%$ de los hogares donde padre y madre están presentes tienen niños pequeños menos de 6 años o personas dependientes de cuidados. En los hogares monoparentales, este tipo de situación están precididos por $81 \%$ de mujeres y 61 en el caso de jefatura masculina (Jaramillo y Ñopo, 2020, p. 12).

\section{Mirada sociológica de la salud mental}

El siguiente testimonio describe las múltiples crisis que golpean la salud mental.

Salícorriendo de casa para dirigirme al terminal terrestre. Llevaba conmigo un bolso negro, una casaca gruesa y el rostro desencajado. Durante el trayecto mis lágrimas corrían por mis mejillas. Mi cuerpo temblaba de miedo y un escalofrío se apoderaba 
de mí cada vez que pensaba en la salud de mi hermano que necesitaba oxígeno con urgencia. Lo encontré boca abajo en la cama. Sus manos estaban enredadas entre los cables que colgaban del parante donde habían varias botellas de suero. Tenía una máscara conectada a un balón de oxígeno.

Pasamos la noche en vela. Recorrimos toda la ciudad en búsqueda de oxígeno. No conseguimos nada ni siquiera para recargar. Tuvimos que encontrar la manera de mandar traer oxígeno desde Lima. Nunca había imaginado vivir algo así. La desesperación al no saber qué sucederá, la preocupación por conseguir dinero para el tratamiento, y el miedo de perder a un ser querido eran tan fuertes que me sentía desfallecer de a pocos. Después de las dos semanas de tormento, la salud de mi hermano empezó a mejorar, sin embargo, la preocupación continuó porque nos quedamos sin dinero y energías.

Mi estado emocional colapsó. Tengo que tomar medicamentos para poder dormir lo cual me afecta, ya que aún no me he curado de la gastritis.

De acuerdo al Diagnóstico 2021, el 60\% (134) de los 232 (40\% del total) estudiantes de la muestra que se contagiaron de Covid-19 han quedado con secuelas. 29\% (170) señalan haber perdido algún familiar en lo que va de la pandemia, mientras que para el 59\% (341) han experimentado la muerte de amigos y amigas. ¿Cómo repercuten todas estas situaciones mencionadas hasta el momento en la salud mental de los y las estudiantes?

¿A que nos referimos con salud mental?

Definir lo que es la salud mental es una tarea compleja. Distinguimos entre problemas de salud mental y patologías en el sentido de "enfermedad mental" que requieren la intervención de un especialista. Con el propósito de ganar claridad sobre el tema, nos atenemos a la distinción que realizó Laing (1993) entre una persona ontológicamente segura y una que no lo es. Haber alcanzado una "posición de seguridad ontológica", supone en primer lugar, que las circunstancias de la vida cotidiana no son amenaza constante para la existencia (Laing, 1993, pp. 35-38). La persona que ha sedimentado una seguridad ontológica en su vida estaría mucho mejor preparada, en cierto modo, para afrontar las vicisitudes de la vida diaria en pandemia. Además de eso, un individuo ontológicamente seguro es capaz de desarrollar relaciones satisfactorias y agradables con los demás. En distinto grado y manera, la pandemia está afectando la salud mental de la población en general. Problemas de salud mental lo sufrimos todos, mientras que una patología se da en circunstancias extremas quizá, sin posibilidad de curación. 
De otro lado, las decisiones que toma la ciencia médica acerca de qué dolencias clasifican como salud mental y cuáles cómo patologías es motivo de un arduo debate que nos lleva al corazón mismo de la biopolítica y al examen de los regímenes de verdad imperantes junto con sus respectivos correlatos expresados en forma de ley, orden, Estado, sociedad civil y políticas de la vida misma (Foucault, 2008, p. 97). Los sistemas de clasificación no solamente son instrumentos de conocimiento sino también de dominación (Bourdieu y Wacquant, 1993). No es nuestra intención calar en todo este entramado, pero si enfatizar que sólo podemos "experimentar las propias condiciones en y a través de las categorías, las clasificaciones y los marcos de referencia de la cultura" contempladas como estructuras que hemos internalizado (Hall, 2010, p. 40).

En tercer lugar tenemos el tema de la manera cómo experimentamos, canalizamos y expresamos nuestras emociones (intensidad, umbral y dirección entre otros aspectos) como algo que es en gran parte aprendido y compartido lo cual nos lleva a ir más allá de una fenomenología existencial que da cuenta de "la experiencia que una persona tiene de su mundo y de sí misma" (Laing, 1993, p. 13). La experiencia social no opera como una esponja o un tamiz que incorpora la realidad a través de las emociones y sensaciones corporales como lo señala Dubet (2010, p. 86), sino más bien implica una manera de construir el mundo.

La pandemia afecta la salud mental de las personas por todo lo examinado anteriormente y se expresa también en la falta de concentración:

\begin{abstract}
A veces me he quedado mirando una lectura leyendo y releyendo, intentado captar la combinación de palabras, relacionar los significados con lo antes aprendido y a eso sumándole qué debía pensar más allá de lo evidente y preguntarme qué habría querido decir el autor o autora. De los últimos meses el peor tiempo fueron los días que ocurrieron las marchas, por esos días pasó algo que ya me había sucedido antes, pero ahora era algo que creo que los demás sentían, no podía concentrarme y literal me pasaba en una carilla por lo menos unos veinte minutos.
\end{abstract}

\title{
7. Agenda para la investigación con perspectiva de género: Impacto de la pandemia en estudiantes
}

De acuerdo a la CEPAL (2021) los gobiernos requerirían ahora realizar importantes esfuerzos para evitar que las múltiples crisis derivadas del Covid-19 no profundicen las brechas en la división sexual del trabajo, la concentración de poder que hace que haya una menor participación de mujeres en los procesos de toma de deci- 
siones sobre las respuestas a la pandemia y exacerbación de patrones culturales y patriarcales que terminan exponiendo a las mujeres a la convivencia con agresores.

Tomaremos como referencia el documento de la CEPAL anteriormente mencionado en diálogo con los hallazgos de la investigación emprendida a través de testimonios de los diarios personales de cinco estudiantes de sexo femenino, sumado a los datos adicionales derivados del Diagnóstico 2021. De esta manera, podríamos resumir y agrupar las temáticas abordadas en cuatro grandes rubros que están mutuamente vinculados unos con otros.

La siguiente agenda propuesta no agota todos los temas que requieren seguir siendo investigados, pero si consideramos que son centrales de ser abordados, además con perspectiva de género y desde un enfoque fenomenológico que si bien esto último no lo hemos abordado en este artículo se refiere a cómo viven los agentes las múltiples crisis y de qué manera eventualmente la propia Universidad podría brindar algún tipo de soporte para los estudiantes:

\section{Tabla 1}

Agenda para la investigación con perspectiva de género: Impacto de la pandemia en estudiantes.

\begin{tabular}{|c|c|}
\hline Temática & Preguntas de investigación con perspectiva de género \\
\hline Crisis socioeconómica. & $\begin{array}{l}\text { ¿De qué manera impacta la crisis socio-económica en la } \\
\text { calidad y modo de vida de los estudiantes y sus familias? } \\
\text { ¿Cuentan las familias con servicios básicos? } \\
\text { ¿Cuántos jefes de hogar han caído en el desempleo? }\end{array}$ \\
\hline $\begin{array}{l}\text { Recurso tiempo: trabajo } \\
\text { remunerado, trabajo doméstico } \\
\text { no remunerado y economía de los } \\
\text { cuidados. }\end{array}$ & $\begin{array}{l}\text { ¿De qué manera este tipo de trabajo llevado a cabo en el } \\
\text { hogar impacta y dialoga con la actividad académica? } \\
\text { ¿Cómo distribuyen su tiempo los alumnos y alumnas que } \\
\text { trabajan? } \\
\text { ¿Cómo se está distribuyendo las labores domésticas y } \\
\text { cuidados al interior de los hogares? } \\
\text { ¿Cuál es la inversión de tiempo en cada una de estas } \\
\text { actividades? }\end{array}$ \\
\hline
\end{tabular}




\begin{tabular}{|c|c|}
\hline Virtualidad de los cursos. & $\begin{array}{l}\text { ¿En qué condiciones se está llevando a cabo la virtualidad } \\
\text { de los cursos tanto a nivel de los estudiantes como de los } \\
\text { profesores? } \\
\text { ¿Cuáles son los requerimientos pedagógicos indispensables } \\
\text { para el buen desempeño docente en la virtualidad? } \\
\text { ¿En qué medida cuentan los estudiantes con dispositivos } \\
\text { electrónicos adecuados? } \\
\text { ¿Cuántas horas invierten los estudiantes en su desempeño } \\
\text { académico? } \\
\text { ¿Cómo impacta la virtualidad en la comunicación entre } \\
\text { estudiantes y docentes? } \\
\text { ¿Cuáles son las dificultades que aparecen para cumplir con } \\
\text { el trabajo remunerado y las labores académicas al mismo } \\
\text { tiempo? } \\
\text { ¿Existen brechas digitales entre varones y mujeres? }\end{array}$ \\
\hline Salud mental. & $\begin{array}{l}\text { ¿Qué tipo de actividades de recreación realizan los } \\
\text { estudiantes en su tiempo libre? } \\
\text { ¿Cuáles son sus hábitos de nutrición y sueño? }\end{array}$ \\
\hline Patrones culturales patriarcales. & $\begin{array}{l}\text { ¿En qué medida existe una mayor exposición de varones y } \\
\text { mujeres a la violencia doméstica al interior de sus hogares } \\
\text { debido al confinamiento? }\end{array}$ \\
\hline
\end{tabular}

\section{Colofón: Las oportunidades que se abren}

Vivimos una situación insufrible que sacude nuestros cimientos, sin embargo, podríamos tomar la situación también como una advertencia para implementar la puesta en práctica de una sabiduría en acción, generar transformaciones viables, exigir al Estado mejora de los servicios, dejar que el miedo no sea el único movilizador en nuestras vidas (Bruce, 2021; Patriau, 2021).

Los siguientes testimonios dan cuenta de la oportunidad de integrar labores de voluntariado y de las dificultades del mismo.

El voluntariado del que formó parte es uno de Educación Sexual Integral (ESI) es $100 \%$ digital y tenemos charlas todos los sábados. Al medio día y a las cuatro de la tarde. Está a cargo de una organización juvenil que aborda temas de derechos sexuales, reproductivos y también sobre igualdad de género. Cuando empezó la emergencia sanitaria por la pandemia, estaba revisando el tema de la violencia 
sexual y noté que la cuarentena había favorecido el incremento de casos, por lo que decidí aportar en algo para ayudar a prevenir estos delitos.

Cuando estaba trabajando aprovechaba antes del desayuno para dejar mi reporte del trabajo listo y después del almuerzo comenzaba a hacer mis llamadas (realizaba acompañamiento por llamadas a adultos mayores vulnerables), las llamadas me tomaban un promedio de tres horas todos los días a veces mucho más y a veces menos. Confiaba en que los profesores grabaran. Dejé de entrar a las clases teóricas de un curso porque la clase comenzaba a las cuatro de la tarde y a esa hora usualmente continuaba con las llamadas. Hace unas semanas me di cuenta que las grabaciones no habían sido subidas."

Las constantes extensiones de la pandemia han llevado a algunas a explorar y cultivar destrezas en múltiples actividades: labores manuales, coser, tejer, un poco de carpintería, tocar instrumentos, todo con ayuda de tutoriales encontrados en YouTube.

Saber de cocina y de medicina natural ancestral, que lo aprendí en mi infancia de mi madre y abuela, fue un factor decisivo para esta labor. A pesar de las dificultades económicas mi hermano salió airoso y logró vencer al virus, aunque todavía sigue en reposo hasta recuperarse por completo. 


\section{Bibliografia}

Ariés, P. (2008). The Hour of Our Death. The Classic History of Western Attitudes Toward Death Over the Last One Thousand Years.

Balbuena, F. (2011). R.D. Laing: un rebelde que desafió el orden psiquiátrico imperante. Revista de la Asociación Española de Neuropsiquiatría. 31 (4).

Bardají, T. (2008). “El diario reflexivo como herramienta de enfermería”. Nursing, 26 (7).

Batthyány, K. (2019). Las políticas y el cuidado en América Latina. Una mirada a las experiencias regionales. Lima: Fondo Editorial de la Universidad del Pacífico, 147-203.

Bauer, M., Gaskell, G. y Allum, N. (2000). "Quality, Quiantity and Knowldege Interests: Avoiding Confusions. Bauer, M. y Gaskell, G. (Eds.). Qualitative Researching with Text, Image and Sound. A practical Handbook. Sage Publications S.A, 3-17.

Beck (2017). La sociedad del riesgo mundial. En busca de la seguridad perdida. Barcelona: Paidós.

Benitez, J. (2018). El derecho a la ciudad como estructura de sentimiento: ¿Nuevas formas pre-emergentes de significar la vivienda y el espacio urbano en la Ciudad Autónoma de Buenos Aires? Cuaderno Urbano. Espacio, cultura, sociedad. 25 (25).

Berger, P. y Luckmann, T. (1979). La construcción social de la realidad. Buenos Aires. Amorrotu editores.

Bourdieu, P. , Wacquant, L. (1992). Una invitación a la sociología reflexiva. Epulibre.

Bourdieu, P., Chamboredon, J.C., Passeron, J.C. (1979). El oficio de sociólogo. Segunda Edición. Siglo Veintiuno Editores.

Bruce, Jorge (10 de mayo, 2021). Conflicto de evitación-evitación. La República. País. Opinión, 9.

Castro-Gómez, S. y Grosfoguel, R. (Eds.) (2007). El giro decolonial. Reflexiones para una diversidad epistémica más allá del capitalismo global. Bogotá: Siglo del Hombre Editores; Universidad Central, Instituto de Estudios Sociales Contemporáneos y Pontificia Universidad Javeriana, Instituto Pensar, prólogo y el artículo de Santiago Castro Gómez.

Castro, J. y Uribe, M. (1998). La educación somática: un medio para desarrollar el potencial humano. Educación física y deporte. 20 (1). Universidad de Antioquía.

Comisión Económica para América Latina y el Caribe (CEPAL) (10 de febrero de 2021). La autonomía económica de las mujeres en la recuperación sostenible y con igualdad. Informe Especial. Covid-19.

Contreras, C. Grandes epidemias de nuestra historia. Crónica del gran encierro. Pensando el Perú en tiempos de pandemia. Asensio, Raúl (Ed.). Lima: IEP. https://iep.org.pe/wpcontent/uploads/2020/06/Cr\%C3\%B3nica-del-Gran-Encierro-1.pdf 
Cook, N. D. (2010). La catástrofe demográfica andina. Perú 1520-1620. Lima: Fondo Editorial de la Pontificia Universidad Católica del Perú.

Comisión de la Verdad y Reconciliación (CVR). (2003). Informe Final. Tomo VIII. Lima.

Dubet, F. (2012). ¿Para qué sirve realmente un sociólogo? Siglo Veintiuno Editores.

Dubet, F. (2010). Sociología de la experiencia. Madrid: Editorial Complutense.

Federici, S. (2019). “Calibán y la bruja”. En Pérez, Leda (Ed.). La economía del cuidado, mujeres y desarrollo: perspectivas desde el mundo y América Latina. Lima: Fondo Editorial de la Universidad del Pacífico, 21-45.

Foucault, M. (2008). Nacimiento de la biopolítica. Fondo de Cultura Económica.

Fraser, N. (2019). "Las contradicciones del capital y los cuidados". En Pérez, Leda (Ed.). La economía del cuidado, mujeres y desarrollo: perspectivas desde el mundo y América Latina. Lima: Fondo Editorial de la Universidad del Pacífico, 69-91.

Fuller, N. (2001). Masculinidades. Cambios y permanencias. Lima: Fondo Editorial de la Pontificia Universidad Católica del Perú.

García, G. (2009). El oficio del sociólogo: la imaginación sociológica. http://bibliotecavirtual. clacso.org.ar/ar/libros/coedicion/olive/10garcia.pdf

Gaskell, G. y Bauer, M. (2000). “Towards Public Accountability: beyond Sampling, Reliability and Validity". Bauer, M. y Gaskell, G. (Eds.). Qualitative Researching with Text, Image and Sound. A practical Handbook. Sage Publications S.A, 336-350.

Giddens, A. (1995). Modernidad e identidad del yo. Barcelona: Ediciones Península.

Giddens, A. (1992). Modernity and Self-Identity. Self and Society in the Late Modern Age. Polity Press.

Guber, R. (2005). El salvaje metropolitano. Reconstrucción del conocimiento social en el trabajo de campo. Buenos Aires: Paidos.

Habermas, J. (1990). Conocimiento e interés. Buenos Aires: Taurus, Alfaguara, S.A.

Habermas, J. (1987 [1968]). Knowledge and Human Interest. [Erkenntnis und Interesse]. Cambridge y Oxford: Polity Press and Basil Blackwell.

Hall, S. (2010). Sin garantías. Trayectorias y problemáticas en estudios culturales. Editado por Restrepo, E., Walsh, C. y Vich, V. Instituto de Estudios Sociales y Culturales Pensar, Universidad Javeriana, Instituto de Estudios Peruanos, Universidad Andina Simón Bolívar, sede Ecuador. Envión Editores.

Jaramillo, M. y Ñopo, H. (2020). Impactos de la pandemia del coronavirus en el trabajo de las mujeres en el Perú. Lima: Ministerio de la Mujer y Poblaciones Vulnerables (MIMP), Programa de las Naciones Unidas para el Desarrollo (PNUD).

Krause, M. (2013). Sentido común y clase social: una fundamentación fenomenológica. Astrolabio. Nueva Época 10. 
Kuhn, T. (2004). La estructura de las revoluciones científicas. Buenos Aires: Fondo de Cultura Económica.

Laing, R. (1993). El yo dividido. Un estudio sobre la salud y la enfermedad. Fondo de Cultura Económica.

Latour, B. (2017). Cara a cara con el planeta. Una nueva mirada sobre el cambio climático alejada de las posiciones apocalípticas. Siglo Veintiuno Editores.

Latour, B. (2007). Nunca fuimos modernos. Ensayo de antropología simétrica. Siglo Veintiuno Editores.

Lauer, M. (2007). Introducción a la pintura peruana del siglo XX. Segunda Edición. Lima: Universidad Ricardo Palma.

Lavado, T. (2017). "El tiempo de las mujeres: la variable perdida del análisis económico." Pensamiento Crítico, 22 (1), Facultad de Ciencias Económicas UNMSM.

Levine, P .(2015). Trauma and Memory. Brain and Body in a Search for the Living Past. Ergos Institute Press.

Lossio, J. (2021). Pandemias y salud pública. Historias de cuarentenas y vacunaciones. Lima: Ministerio de Cultura. Bicentenario Perú 2021.

Mannarelli, M.E., Angélica Motta, Carmen Yon, Erika Figueroa y Katherine Soto (2020). "Mujeres, género y pandemia en el Perú". Ministerio de Salud. Grupo temático de Ciencias Sociales. Por una nueva convivencia. La sociedad peruana en tiempos de COVID-19. Escenarios, propuestas de política y acción pública. https://www.clacso. org/wp-content/uploads/2020/05/Por-una-Nueva-Convivencia.pdf

Naciones Unidas de Colombia, Organización Panamericana de la Salud, Organización Mundial de la Salud (2020). Resiliencia en tiempos de pandemia. Claves para fortalecer los recursos psicológicos en el aislamiento y distanciamiento social. Apuntes para reflexionar.

Nugent, J. (1991)“Las perspectivas del mundo de la vida en las investigaciones de las ciencias sociales". Debates en Sociología, 16. Pontificia Universidad Católica del Perú (PUCP).

Ortner, S. (1979). ¿Es la mujer con respecto al hombre lo que la naturaleza con respecto a la cultura?. En Harris, O. y Young, K. (compiladoras). Antropología y feminismo. Barcelona: Editorial Anagrama.

Patriau, E. (10 de mayo, 2021). Entrevista. Paula Távara. Politóloga de la Pontificia Universidad Católica del Perú. La República. País. Política, 4.

Pérez, L. (2019 a). Introducción. Pérez, L. (Ed.). La economía del cuidado, mujeres y desarrollo: perspectivas desde el mundo y América Latina. Lima: Fondo Editorial de la Universidad del Pacífico, 9-17 
Pesantes, M. y Gianella, C. (2020) ¿Y la salud intercultural?: Lecciones desde la pandemia que no debemos olvidar. Mundo Amazónico, 11 (2). Dossier: Reflexiones y perspectivas en torno a la pandemia del COVID-19, 93-110.

Programa de las Naciones Unidad para el Desarrollo (PNUD). (2020). Sacasa. M. El progreso humano al borde del colapso. https://www.pe.undp.org/content/peru/es/home/ presscenter/articles/2020/el-progreso-humano-al-borde-del-colapso.html

Quijano, A. (2014). Des/colonialidad y bien vivir. Un nuevo debate en América Latina. Lima: Cátedra América Latina y la colonialidad del poder. Universidad Ricardo Palma. Editorial Universitaria.

Quijano, A. (1980). Dominación y cultura. Lo cholo y el conflicto cultural en el Perú. Lima: Mosca Azul Editores.

Rorty, R. (1996). Método, ciencia y esperanza social. En Consecuencias del pragmatismo. Madrid:Tecnos.

Rorty, R. (1992). Contingencia, ironía y solidaridad. Barcelona: Paidós.

Trischler, H. (2017). El Antropoceno ¿un concepto geológico o cultural, o ambos? Desacatos 54. México.

Villalta, M. (2010). Factores de resiliencia asociados al rendimiento académico en estudiantes de contextos de alta vulnerabilidad social. Revista de Pedagogía, 88(31), 159-188. Universidad Central de Venezuela. https://www.redalyc.org/pdf/659/65916617007. pdfg 